\title{
Intervention, Causal Reasoning, and the Neurobiology of Mental Disorders: Pharmacological Drugs as Experimental Instruments
}

\author{
Jonathan Y. Tsou \\ Department of Philosophy \& Religious Studies, Iowa State University
}

Forthcoming in Studies in History and Philosophy of Biological and Biomedical Sciences 


\begin{abstract}
:
In psychiatry, pharmacological drugs play an important experimental role in attempts to identify the neurobiological causes of mental disorders. Besides being developed in applied contexts as potential treatments for patients with mental disorders, pharmacological drugs play a crucial role in research contexts as experimental instruments that facilitate the formulation and revision of neurobiological theories of psychopathology. This paper examines the various epistemic functions that pharmacological drugs serve in the discovery, refinement, testing, and elaboration of neurobiological theories of mental disorders. I articulate this thesis with reference to the history of antipsychotic drugs and the evolution of the dopamine hypothesis of schizophrenia in the second half of the twentieth century. I argue that interventions with psychiatric patients through the medium of antipsychotic drugs provide researchers with information and evidence about the neurobiological causes of schizophrenia. This analysis highlights the importance of pharmacological drugs as research tools in the generation of psychiatric knowledge and the dynamic relationship between practical and theoretical contexts in psychiatry.
\end{abstract}

Keywords: psychiatry, pharmacology, neurobiology, dopamine hypothesis of schizophrenia, intervention, causal reasoning. 


\section{Introduction}

Pharmacological research has played a central role in the development of neurobiological theories of psychopathology. Effective pharmacological treatments of mental disorders have often been discovered through serendipitous experimental results, e.g., the first antidepressant drug was discovered accidentally during attempts to find a treatment for tuberculosis (Healy, 1997, ch. 2; López-Muñoz et al., 2007). These fortuitous discoveries have often shed important insights about the neurobiological basis of mental disorders, which in turn have allowed for refinements in pharmacological treatments and revisions of neurobiological theories. This paper examines the ways that pharmacological findings in applied contexts contribute to neurobiological knowledge about mental disorders in research contexts, focusing on the coevolution of antipsychotic drugs and neurobiological theories of schizophrenia in the second half of the twentieth century. While the discussion of this paper focuses on the utilization of antipsychotic drugs in schizophrenia research, the resulting analysis is more broadly applicable to the general use of pharmacological drugs in neurobiological research on psychopathology.

The main argument advanced in this paper is that interventions with psychiatric patients utilizing pharmacological drugs provide researchers with information about the neurobiological causes of mental disorders that cannot be obtained in other ways. In articulating this argument, my analysis draws upon philosophical accounts of science that emphasize the importance of manipulability and intervention in experimental contexts (Hacking, 1983; Franklin, 1996; Woodward, 2003b). The paper proceeds as follows. I begin by reviewing the history of antipsychotic drugs initiated by the discovery of chlorpromazine in the 1950s, which stimulated research on other neuroleptic drugs and resulted in the development of atypical antipsychotic drugs in the 1990s. I subsequently discuss the history of neurobiological theories of 
schizophrenia, focusing on the historical development of the dopamine hypothesis of schizophrenia. From this historical case, I articulate various roles that antipsychotic drugs play in the formulation, revision, and refinement of neurobiological theories of schizophrenia. ${ }^{1}$ I argue that four interrelated functions that pharmacological drugs serve in neurobiological research are: (1) providing tools for accessing and detecting the neurobiological causal structure of mental disorders, (2) aiding the formulation of neurobiological hypotheses, (3) contributing to the testing of neurobiological theories, and (4) facilitating the revision of neurobiological theories. This argument elucidates the ways that experimental practices in pharmacology contribute to the generation of neurobiological knowledge about mental disorders.

\section{The discovery and evolution of antipsychotic drugs}

The following section examines the discovery and subsequent evolution of antipsychotic drugs in the second half of the twentieth century. ${ }^{2}$ The antipsychotic properties of the first neuroleptic drug (chlorpromazine) were discovered by accident in the early 1950s, which led to the development of other antipsychotic drugs in the 1960s and 1970s. The unwanted extrapyramidal side-effects associated with first generation antipsychotic drugs eventually led to the development of second generation (“atypical”) antipsychotic drugs in the 1990s.

\footnotetext{
${ }^{1}$ I have elsewhere discussed the important methodological role that history can play in informing philosophical analyses of psychiatry (Tsou, 2011). This paper is intended to offer a contribution to historically-informed approaches to philosophy of psychiatry and to the broader philosophy of scientific experimentation literature (Hacking, 1983; Franklin, 1986; Galison, 1987; Radder, 2003).

${ }^{2}$ For a more comprehensive discussion of the history of antipsychotic drugs, see Frankenburg (1994), Shen (1999), Healy (2002), López-Muñoz et al. (2005), and Ban (2007).
} 


\subsection{The discovery of chlorpromazine}

The antipsychotic properties of chlorpromazine were discovered accidentally in the 1950s during trials designed to identify an anesthetic agent for treating soldiers (López-Muñoz et al., 2005, 114—118; Shen, 1999, pp. 407—408). In the early 1950s, a French military surgeon, Henri Laborit, was experimenting with various drugs that could potentially treat surgical shock, which is an acute and sometimes fatal state that would occur during surgery (McKim, 2007, pp. 287-288). Laborit hypothesized that this state of shock is caused by the excessive release of neurotransmitters such as epinephrine, acetylcholine, and histamine, and he experimented with drugs that were known to block the release of these substances, including antihistamines. During this period, Laborit was working closely with the French pharmaceutical company, RhônePoulenc, who supplied him with different kinds of antihistamines. In 1951, Rhône-Poulenc asked Laborit to try a drug called RP-4560 (chlorpromazine), which was an antihistamine that the company synthesized a few years earlier, but had rejected because of its strong sedative properties. Laborit's trials with chlorpromazine were successful in preventing surgical shock, and Laborit reported that he was able to put surgical patients into an "artificial hibernation," wherein patients would not lose consciousness, but would become sleepy and disinterested with everything going on around them (Laborit \& Huguenard, 1951). Laborit speculated about the potential therapeutic applications of chlorpromazine in psychiatry as a "vegetative stabilizer" (Laborit, Huguenard, \& Alluaume, 1952), and he suggested to some psychiatrist colleagues that the drug might be useful for treating agitated mental patients (Healy, 2002, pp. 81—82; Ban, 2007, p. 496).

The most important clinical trials with chlorpromazine on psychiatric patients were conducted by two Parisian psychiatrists, Jean Delay (a professor of psychiatry at the Sorbonne 
and director of the Hôpital Saint-Anne) and Pierre Deniker (the men's service chief at Hôpital Saint-Anne), who had learned of Laborit's trials and requested samples of chlorpromazine from Rhône-Poulenc (López-Muñoz et al., 2005, p. 118). Beginning in 1952, Delay and Deniker investigated the effects of chlorpromazine on various mental patients at the Hôpital Saint-Anne in Paris, and they reported some striking successes (Delay \& Deniker, 1952a, 1952b, 1952c; Delay, Deniker, \& Harl, 1952a, 1952b; Delay et al., 1952). While chlorpromazine was not effective at treating depression, it had dramatic therapeutic effects on patients in states of agitation, mania, mental confusion, and acute psychosis (López-Muñoz et al., 2005, p. 120). The researchers also described the clinical capacity of chlorpromazine to slow motor activity, cause affective indifference, and neutralize emotions as a "neuroleptic syndrome” (Delay \& Deniker, 1952a); chlorpromazine and subsequent drugs that produced similar motor side-effects were classified as "neuroleptics.”3 Delay and Deniker's pioneering research in 1952—along with other reports of successful treatment of psychiatric patients with chlorpromazine around the world (see Ban, 2007, p. 496)—set the stage for the widespread introduction of chlorpromazine in psychiatry.

In November 1952, chlorpromazine was made available for prescription in France under the tradename Largactil, which made the drug widely available to clinicians and psychiatrists around the world (Shen, 1999, pp. 408—409). By the end of 1955, successful treatments of schizophrenic patients using chlorpromazine were reported in numerous countries across the world, including Switzerland, the United Kingdom, Germany, Hungary, Canada, Peru, the United States, Australia, and the USSR (Ban, 2007, p. 296). In 1954, Heinz Lehmann—a

\footnotetext{
${ }^{3}$ While the term "neuroleptic" was widely used and accepted in Europe, it was regarded as inappropriate in the United States to classify a family of drugs by their adverse side-effects rather than by their therapeutic qualities (López-Muñoz et al., 2005, p. 118). In the United States, these drugs were initially classified as "tranquillizers," then "major tranquillizers," and eventually "antipsychotic drugs" (King \& Voruganti, 2002). For purposes of consistency, I refer to these drugs in this paper as "antipsychotics" or "typical antipsychotics."
} 
German born Canadian psychiatrist—was the first to suggest that chlorpromazine works by selectively inhibiting “affective drive” (Lehmann, 1954; Lehmann \& Hanrahan, 1954), and his research was extremely influential in promoting the use of chlorpromazine in North American psychiatry. Chlorpromazine was approved in the United States in May 1954 and marketed under the tradename Thorazine (López-Muñoz et al., 2005, p. 125). The introduction of chlorpromazine in the US was a major factor in the mass deinstitutionalization of mental patients in the 1960s and 1970s, in which many institutionalized patients no longer needed to be confined to asylums since they were able to live in community settings (Grob, 1991, 1995). In 1957, the American Public Health Association jointly awarded the prestigious Lasker Prize for Medicine to Laborit, Deniker, and Lehmann for discovering the antipsychotic properties of chlorpromazine (Ban, 1994; Healy, 2002, pp. 125—128).

\subsection{Typical vs. atypical antipsychotic drugs}

The clinical success of chlorpromazine stimulated the search for other antipsychotic drugs. While chlorpromazine was the main antipsychotic drug prescribed in the United States throughout the 1960s and 1970s, after the introduction of chlorpromazine, many other drugs with similar antipsychotic effects were developed (Shen, 1994, 1999). In the late 1950s and 1960s, some of the antipsychotic drugs approved in the United States included (see Janowsky, 2004, pp. 78-81): thioridazine (Mellaril), trifluoperazine (Stelazine), perphenazine (Trilafon), triflupromazine (Vesprin), fluphenazine (Prolixin), haloperidol (Haldol), and thiothixene (Navane). ${ }^{4}$ A common problem with all of these first-generation (“typical”) antipsychotic drugs

\footnotetext{
${ }^{4}$ For information on antipsychotic drugs approved in the United Kingdom, see Healy (2004, pp. 96-97) and Wheatley (2004, p. 88).
} 
was the presence of unwanted motor side-effects or extrapyramidal symptoms (EPS) that resemble the symptoms of Parkinson's disease. EPS include dystonia (muscular rigidity), dyskinesia (abnormal motion of voluntary and involuntary muscles), akinesia (inability to initiate movement), akasthesia (inability to remain still), tremors, arching of the back, and twisted posture (Kring et al., 2007, p. 375). In the early 1950s, EPS were described and recognized as side-effects associated with chlorpromazine (Delay \& Deniker, 1952c; Labhardt, 1954; Lehmann \& Hanrahan, 1954). In a 1961 report, the prevalence of EPS among patients treated with antipsychotic drugs was estimated to be 38.9\% (Ayd, 1961). At the time, many clinicians and pharmacologists believed that there was an absolute connection between EPS and the clinical efficacy of antipsychotic drugs, with stronger antipsychotic effect being associated with more EPS (Shen, 1999, p. 409). This belief was eventually refuted with the development of secondgeneration (“atypical”) antipsychotic drugs.

The first atypical antipsychotic drug developed was clozapine. While this drug was originally synthesized in 1958, it was not introduced in the United States until 1990 due to safety concerns (Meyer \& Simpson, 1997; Shen, 1999, p. 409). Clozapine was created in Bern, Switzerland, and it was first investigated by a group of Austrian and German psychiatrists whoin the early 1960s—-were working to refute the common pharmacological belief that EPS and strength of antipsychotic effect were causally linked (Hippius, 1996). In the 1960s, several clinical trials with clozapine demonstrated that the drug had a strong clinical antipsychotic effect with minimal EPS (Bente et al., 1966; Gross \& Langner, 1966; Angst et al., 1971). ${ }^{5}$ The ability of clozapine to treat psychotic symptoms without inducing EPS demonstrated to pharmacologists that the clinical efficacy of antipsychotics could be separated from their unwanted

\footnotetext{
${ }^{5}$ Because of the lack of EPS associated with clozapine, some researchers did not consider it as a real "neuroleptic" (see note 3 above). This led to a situation where the drug manufacturer of clozapine was hesitant to introduce the drug, not because of its lack of clinical efficacy, but because of its lack of side-effects (Hippius, 1989, p. S4).
} 
extrapyradmidal side-effects (Meyer \& Simpson, 1997). Clozapine was introduced in a number of European countries in the late 1960s; however, it was withdrawn from the market (in some countries) in the mid-1970s due to a report from Finland of life-threatening cases of agranulocytosis (i.e., a dangerous lowering of the number of white blood cells) associated with clozapine treatment (Hippius, 1989, p. S4; Healy, 2002, pp. 238-244). In the following decade, fears about the safety of clozapine gradually allayed, and it became understood that agranulocytosis would appear among a small percentage of patients treated with clozapine, but that fatal instances could be avoided through close blood monitoring (Hippius, 1989, p. S4). In the United States, the introduction of clozapine was facilitated by a landmark study that demonstrated the effectiveness of clozapine (compared to chlorpromazine) on treatment-resistant schizophrenic patients (Kane et al., 1988). Eventually, clozapine was introduced to the United States in 1990 (Janowsky, 2004). After the introduction of clozapine in the US, a number of other atypical antipsychotic drugs were quickly developed. The atypical antipsychotics introduced in the 1990s and 2000s included (see Shen, 1999, p. 410; Janowsky, 2004, pp. 8081): risperidone (Risperdal), olanzapine (Zyprexa), quetiapine (Seroquel), ziprasidone (Geodon), and aripiprazole (Abilify). All antipsychotic drugs currently under development are of the atypical type (McKim, 2007, p. 284).

\section{The dopamine hypothesis of schizophrenia}

In the following section, I examine the methodological utilization of antipsychotic drugs as experimental instruments for investigating the neurobiological basis of schizophrenia. In addition to being employed in applied contexts as tools for treating psychiatric patients diagnosed with schizophrenia, antipsychotic drugs — and pharmacological drugs more 
generally_play a critical role in research contexts as experimental instruments or artifacts for identifying the neurobiological causes of schizophrenia. Below, I discuss the role of antipsychotic drugs (and other pharmacological drugs) in the formulation, refinement, and revision of the dopamine hypothesis of schizophrenia.

\subsection{The mesolimbic pathway and positive symptoms}

The dopamine hypothesis of schizophrenia has been the dominant neurobiological theory of schizophrenia since the 1970s (Kring et al., 2007, pp. 363-365; Carlson, 2008, pp. 460466). ${ }^{6}$ In its original formulation, the dopamine hypothesis suggested that the symptoms of schizophrenia are caused by excessive activity of the neurotransmitter dopamine. Since the early1980s (Strauss, Carpenter, \& Bartko, 1974; Wing, 1978; Crow, 1980a, 1980b; Andreason \& Olsen, 1982), the symptoms of schizophrenia have been distinguished into “positive” and “negative” symptoms:

(1) Positive symptoms (psychological excesses): delusions, hallucinations, and thought disorder.

(2) Negative symptoms (psychological deficits): flattened affect, poverty of speech, lack of motivation, and social withdrawal.

A more refined formulation of the dopamine hypothesis maintains that the positive (psychotic) symptoms of schizophrenia are caused by excessive dopamine activity. While this hypothesis is limited insofar as dopamine activity will not provide a complete explanation for the causes of

\footnotetext{
${ }^{6}$ For a more comprehensive discussion of the history of the dopamine hypothesis, see Seeman (1987), Howes and Kapur (2009), and Kendler and Schaffner (2011).
} 
schizophrenia, this theory has taken researchers a long way towards understanding the complex neurobiological causes of the positive and negative symptoms schizophrenia.

Evidence for the dopamine hypothesis of schizophrenia is directly linked to pharmacological interventions with psychiatric patients, and more generally, research on the effects of various pharmacological drugs. All antipsychotic drugs—-both typical and atypical— that can successfully treat the positive symptoms of schizophrenia are dopamine antagonists that decrease the activity of dopamine. The earliest formulations of the dopamine hypothesis (van Rossum, 1966, 1967; Matthysse, 1973; Meltzer \& Stahl, 1976)—which were based on the finding that typical antipsychotics increase the metabolism of dopamine in mice (Carlsson \& Lindqvist, 1963)—implicated a general overstimulation of dopamine pathways in the brain. A key discovery in the 1970s that further implicated the role of dopamine in schizophrenia was the finding that clinical effectiveness of typical antipsychotic drugs (e.g., chlorpromazine, haloperidol) is directly related to their affinity for dopamine receptors (Seeman \& Lee, 1975; Creese, Burt, \& Snyder, 1976; Seeman et al., 1976). Indirect evidence for the dopamine hypothesis was provided by the fact that typical antipsychotic drugs cause extrapyramidal sideeffects similar to the symptoms of Parkinson's disease, and Parkinson's is known to be caused in part by low levels of dopamine (Kring et al., 2007, p. 363). Another important piece of support for the dopamine hypothesis was the finding in the early 1970s that stimulant drugs (e.g., cocaine, amphetamine, L-DOPA) with opposite pharmacological effects as antipsychotics (i.e., dopamine agonists), when taken in sufficiently large doses, can induce an "amphetamine psychosis” in non-schizophrenic individuals (Griffiths, Oates, \& Cavanaugh, 1968; Angrist \& Gershon, 1970; Bell, 1973). Amphetamine psychosis is characterized by symptoms indistinguishable from the positive symptoms of schizophrenia (e.g., paranoid delusions, 
hallucinations, and thought disorder), and this state can be treated with antipsychotic drugs (Ellinwood, 1967; Ellinwood, Sudilovsky, \& Nelson, 1973; McKim, 2008, p. 461).

The original dopamine hypothesis that suggests that schizophrenia is caused by excessive dopamine activity is complicated by the fact that antipsychotic drugs have ubiquitous effects on different dopamine pathways in the brain. In the early 1990s, a further elaboration of the dopamine hypothesis was articulated in a landmark paper by Davis and his colleagues (Davis et al., 1991), which expanded the scope of the original dopamine hypothesis by theorizing about different dopamine systems and receptors (see Healy, 2002, chs. 5-6). This revised version of the dopamine hypothesis suggested that excessive dopamine activity in the mesolimbic pathway is responsible for the positive symptoms of schizophrenia, while deficient dopamine activity in the mesocortical pathway is responsible for the negative symptoms. The mesolimbic dopamine pathway (which is involved in motivation and reinforcement) is a neural pathway that originates in the ventral tegmental area and projects to the hypothalamus, amygdala, hippocampus, and nucleus accumbens (McKim, 2007, pp. 289-290; Kring et al., 2007, p. 364). The initial hypothesis that schizophrenia is caused by excessive dopamine activity was refined to the narrower hypothesis that the positive (psychotic) symptoms are caused by excessive dopamine activity in the mesolimbic pathway. This excessive dopamine activity is theorized as being caused by the hyperstimulation of $\mathrm{D}_{2}$ dopamine receptors (the main dopamine receptor subtype in this area) given that antipsychotic drugs exert their therapeutic effect primarily by blocking $\mathrm{D}_{2}$ receptors (Abi-Dargham, 2004, p. S2). 


\subsection{The mesocortical pathway and negative symptoms}

The revised dopamine hypothesis suggests that deficient dopamine activity in the mesocortical pathway —and in particular, the prefrontal cortex —results in the hypostimulation of $\mathrm{D}_{1}$ receptors (the main dopamine receptor subtype in this area), which is responsible for the negative symptoms and cognitive impairments associated with schizophrenia (Abi-Dargham, 2004, p. S2). The mesocortical dopamine pathway originates in the ventral tegmental area and projects to the prefrontal cortex (Kring et al., 2007, p. 364). The theory that negative symptoms are caused by deficient dopamine activity in the mesocortical system is supported by the findings that cognitive impairment is associated with dysfunction in the prefrontal cortex (the terminal region of the mesocortical pathway) and that dopamine depletion in the prefrontal cortex (using dopamine antagonists) in animals induces cognitive impairment (Sawaguchi \& Goldman-Rakic, 1994). Moreover, deficits in dopamine transmission in the mesocortical pathway are thought to be causally related to dopamine overactivity in the mesolimbic pathway. The prefrontal cortex projects to limbic areas innervated by dopamine such that deficient dopamine activity in the prefrontal cortex fails to exert inhibitory control over dopamine neurons in the limbic area, resulting in excessive dopamine activity in the mesolimbic system (Kring et al., 2007, pp. 364— 365; Carlson, 2008, pp. 468-469). Hence, the original dopamine hypothesis posited in the 1970s was expanded from the theory that schizophrenia is caused by excessive dopamine activity to the hypothesis that schizophrenia is caused by a dysregulation of dopamine, with a deficiency of dopamine activity in the prefrontal cortex resulting in an excess of dopamine activity in the mesolimbic pathway.

Studies on drugs such as phencyclidine (PCP) and ketamine, which can produce the full range of symptoms associated with schizophrenia, further support and help to elaborate the 
hypothesis that the negative symptoms and cognitive impairment of schizophrenia are related to deficient dopamine activity in the mesocortical pathway (Carlson, 2008, pp. 467-469). The negative and cognitive symptoms produced by PCP are related to a decrease of dopamine activity in the prefrontal cortex. Animal studies have found that chronic PCP treatment results in cognitive and behavioral impairments, that degree of impairment is correlated with decrease in dopamine transmission in the prefrontal cortex, and that this impairment can be improved with clozapine treatment (Jentsch \& Roth, 1999; Jentsch et al., 1999). These findings are significant since PCP and ketamine are NMDA receptor antagonists (which block the transmission of the neurotransmitter glutamate) and NMDA receptors and dopamine receptors function to facilitate transmission of one another (Carlson, 2008, pp. 467—468). This suggests that drugs like PCP and ketamine suppress activity of dopamine in the prefrontal cortex through their link with NMDA glutamate receptors. ${ }^{7}$ Studies with PCP also support the theory that deficient dopamine activity in the prefrontal cortex (associated with negative symptoms) causes excessive dopamine activity in the mesolimbic pathway (associated with positive symptoms). One study (Jentsch et al., 1998) found that infusing PCP directly in the prefrontal cortex increases dopamine activity in the nucleus accumbens (the terminal region of the mesolimbic pathway). Another study (Youngren et al., 1999) found that injections of the atypical antipsychotic drug clozapine—which can treat both negative and positive symptoms—increases dopamine activity in the prefrontal cortex and decreases dopamine activity in the nucleus accumbens. ${ }^{8}$ Research indicates that decreased dopamine activity in the prefrontal cortex causes increased dopamine activity in the

\footnotetext{
${ }^{7}$ This has stimulated important research on the role of glutamate in schizophrenia (e.g., see Olney \& Farber, 1995; Tamminga, 1998; Goff \& Coyle, 2001; Carlsson et al., 2001; Laruelle, M., Kegeles, L. S., \& Abi-Dargham, 2003; Coyle, 2006), which suggests that decreased glutamate activity (hypofunction) in the prefrontal cortex results in dysregulation of dopamine in the mesocortical and mesolimbic pathways.

${ }^{8}$ This would suggest that direct NMDA agonists that increase glutamate activity in the prefrontal cortex could potentially treat the negative symptoms of schizophrenia; however, these drugs (e.g., NMDA) cannot be utilized since they increase the risk of seizures and may cause brain damage through excitotoxicity (Carlson, 2008, p. 469).
} 
mesolimbic pathway via interactions among dopamine, glutamate, and GABA in the ventral tegmental area (Carr \& Sesack, 2000; Carlson, 2008, p. 468).

\subsection{The nigrostriatal pathway and extrapyramidal symptoms}

The dopamine hypothesis can also account for the different pharmacological profiles of typical and atypical antipsychotic drugs. In addition to the mesolimbic pathway and mesocortical pathway, another dopamine system relevant for understanding schizophrenia—and in particular, the extrapyramidal side-effects of antipsychotic drugs - is the nigrostriatal pathway. The nigrostriatal dopamine pathway (which plays a key role in the control of movement) originates in the midbrain in the substantia nigra and projects to the basal ganglia (McKim, 2007, pp. 288289). While the therapeutic effects of antipsychotic drugs on the mesolimbic system are thought to be responsible for treating the positive symptoms of schizophrenia, the effects of these drugs on the nigrostriatal system (i.e., decreasing dopamine activity) are responsible for EPS (McKim, 2007, p. 289). As discussed earlier, compared to typical antipsychotic drugs, atypical antipsychotic drugs (e.g., clozapine, resperidone) are more effective at treating the negative symptoms of schizophrenia and have minimal Parkinsonian EPS. Pharmacologically, differences between typical and atypical antipsychotics can explain these differential effects. The EPS associated with typical antipsychotics are caused by decreased dopamine activity in the nigrostriatal pathway due to the blocking of $\mathrm{D}_{2}$ receptors in the basal ganglia (the terminal region of the nigrostriatal pathway); atypical antipsychotics avoid blocking dopamine in the nigrostriatal system because they do not have a high affinity for $\mathrm{D}_{2}$ dopamine receptors, but have high affinities for the $\mathrm{D}_{3}$ and $\mathrm{D}_{4}$ receptor subtypes, which are not found in high numbers in the basal ganglia (Landwehrmeyer, Mengod, \& Palacios, 1993; Primus et al., 1997). Hence, atypical 
antipsychotics work by depressing dopamine activity in the mesolimbic system without having a great affect on the nigrostriatal system.

Differences in the pharmacological profiles of typical and atypical antipsychotics have also implicated a role for serotonin in schizophrenia. Besides a weaker blockade effect on $\mathrm{D}_{2}$ dopamine receptors, atypical antipsychotics have a stronger blockade effect on $5-\mathrm{HT}_{2 \mathrm{~A}}$ serotonin receptors (McKim, 2007, pp. 290—292). Both typical and atypical antipsychotics are dopamine and serotonin antagonists, and both have some blocking activity on 5- $\mathrm{HT}_{2 \mathrm{~A}}$ receptors; however, this blockade effect is much stronger for atypical antipsychotics (Seeman \& van Tol, 1994). This suggests at least three hypotheses for why atypical antipsychotics are not associated with EPS (McKim, 2007, pp. 290_291): (i) they have high affinity for $\mathrm{D}_{3}$ and $\mathrm{D}_{4}$ receptors, (ii) they have low affinity for $\mathrm{D}_{2}$ receptors, and (iii) their $5-\mathrm{HT}_{2 \mathrm{~A}}$ activity cancels their $\mathrm{D}_{2}$ activity. In addition, serotonin may also play a role in the appearance of positive symptoms. Hallucinogen drugs such as LSD are 5- $\mathrm{HT}_{2 \mathrm{~A}}$ agonists, and increasing the activity of serotonin functions to increase the response of glutamate receptors in the frontal cortex, which causes the hallucinations associated with hallucinogen drugs (McKim, 2007, pp. 291—292, ch. 16). This suggests that atypical antipsychotics may reduce positive symptoms (viz., hallucinations) by blocking 5-HT $2 \mathrm{~A}$ receptors and the hallucinations associated with schizophrenia may, in part, be caused by excessive serotonin activity.

\section{Functions of pharmacological drugs as experimental instruments}

Reflections on the historical development of pharmacological treatments for schizophrenia and neurobiological theories of schizophrenia reveal important functions that drugs carry out - in the contexts of discovery and justification-as experimental instruments. In 
the following section, I argue that four important (interrelated) epistemic functions that pharmacological drugs fulfill in the context of neurobiological research on mental disorders include: (1) accessing and detecting the existence of a stable neurobiological causal structure, (2) generating hypotheses about neurobiological causes, (3) testing neurobiological theories, and (4) facilitating the revision of neurobiological theories. This discussion elucidates multiple ways in which pharmacological drugs serve as experimental instruments in providing researchers with information about the neurobiological causes of schizophrenia.

\subsection{Accessing and detecting stable neurobiological kinds}

The most basic function that pharmacological drugs serve in the context of discovery is as tools for accessing and detecting the existence of a stable neurobiological causal structure of mental disorders that cannot be obtained in other ways. While the "psychopharmacology revolution" in psychiatry typically refers to the pioneering use of pharmacological drugs to treat schizophrenia and depression in the mid-1950s (Baumeister \& Hawkins, 2005; Bhatara, LópezMuñoz, \& Gupta, 2005), this revolution also ushered in a new research paradigm in psychiatry wherein pharmacological drugs were adopted as tools for identifying and discriminating distinctive mental disorders (Healy, 2002, pp. 107-109). In this new paradigm, researchers used the differential response of patients to various drug treatments as a means for distinguishing between mental disorders with different neurobiological bases. Jennifer Radden (2003, 2009, ch. 4) has aptly dubbed this practice of individuating different psychiatric categories on the basis of psychopharmacological effects as drug cartography. ${ }^{9}$ An important methodological feature of

\footnotetext{
${ }^{9}$ Radden (2003, 2009, ch. 4) criticizes the practice of drug cartography for its assumption that effective treatment of a psychological disorder proves that the disorder has a particular neurobiological cause. In discussing the experimental function of drugs to detect distinctive mental disorders, I do not want to suggest that effective treatment of a disorder proves that a disorder has a particular neurobiological cause. Rather, I want to make the
} 
this practice is the use of pharmacological interventions with psychiatric patients as a means for detecting the existence of mental disorders as distinctive neurobiological entities or kinds. The "kinds" of mental disorders that pharmacological interventions can detect and individuate are usefully understood as mechanistic property cluster (MPC) kinds, i.e., kinds constituted by mutually reinforcing networks of (stable) causal mechanisms (see Kendler, Zachar, \& Craver, 2011). In this paper, I suggest that pharmacological drugs are capable of detecting MPC kinds that are constituted by stable neurobiological mechanisms. ${ }^{10}$

The ways in which psychiatrists use pharmacological drugs to detect the existence of neurobiological kinds is consonant with philosophical accounts of natural science (e.g., see Hacking, 1983; Cartwright, 1983, ch. 5; Ackermann, 1985; Giere, 1988, ch. 5) that emphasize how intervening with and manipulating theoretical entities provides reasons for believing in their existence (cf. Morrison, 1990). While philosophers such as Hacking (1983) maintain that experimentation with theoretical entities (e.g., utilizing electrons in electron guns) provides evidence for their real existence, my analysis takes the more liberal stance that experimentation on entities and measuring their properties can also sometimes provide reasons for belief in their existence (Franklin, 1996, 2010). In the case of mental disorders, there is defeasible evidence for believing that a mental disorder is a real theoretical entity (as opposed to a social construction) when it can be manipulated in systematic and predictable ways by pharmacological drugs. ${ }^{11}$ The

weaker claim that drugs are useful exploratory experimental tools that allow researchers to access the hidden neurobiological basis of mental disorders and formulate hypotheses about the (neurobiological) distinctiveness of disorders.

${ }^{10}$ My analysis assumes that mechanisms are complex systems of entities and activities that are organized in a way to produce regular changes (see Bechtel \& Richardson, 1996; Glennan, 1996, 2002; Machamer, Darden, \& Craver, 2000; Craver \& Darden, 2001; Machamer, 2004; Tabery, 2004). The various “neurobiological causes” (e.g., excessive dopamine activity in the mesolimbic pathway, deficient dopamine activity in the prefrontal cortex) that I discuss in this paper can be understood as neurobiological mechanisms in this sense.

${ }^{11}$ In this paper, the significance of whether mental disorders are 'real theoretical entities' concerns the stability of these objects. Hacking (1999, ch. 4; 2007) has suggested that the objects of classification in the human sciences (e.g., psychiatry) are inherently unstable ("moving targets") because they are subject to looping effects, i.e., social 
fact that the distinctive symptoms of a disorder can be reliably treated (or induced) by pharmacological interventions provides evidence that what is being manipulated is a stable MPC kind. In the case of schizophrenia research, successfully treating schizophrenic patients with antipsychotic drugs provides evidence for the existence of schizophrenia as a real theoretical entity by suggesting that it has a distinctive and stable neurobiological causal structure.

Similarly, the fact that patients with bipolar disorder respond positively to lithium treatmentwhereas patients with unipolar depression do not (McKim, 2007, ch. 14)—provides reasons for believing that bipolar disorder is a distinctive neurobiological mental disorder. In cases where several mental disorders (e.g., depression, generalized anxiety disorder, obsessive-compulsive disorder) respond positively to the same pharmacological treatment (e.g., SSRIs), this suggests that there are common neurobiological mechanisms at work and that these disorders share a similar neurobiological causal structure.

\subsection{Generating neurobiological hypotheses}

A related but more specific function that pharmacological drugs serve in the context of discovery is to facilitate the generation, formulation, and articulation of causal neurobiological hypotheses (cf. Schaffner, 1993, ch. 2). Pharmacological drugs realize this particular goal by allowing researchers to draw inferences about the neurobiological causes of mental disorders based on how patients with such disorders respond to particular drug treatments. In this process, pharmacological drugs operate as technologies or instruments that—by manipulating mental disorders_-play a crucial role in revealing important causal regularities and properties of

feedback effects that constantly change the people being classified. I have elsewhere argued (Tsou, 2007) that looping effects do not necessarily render the objects of classification in psychiatry (and the human sciences more generally) unstable in the way suggested by Hacking. Psychiatric disorders that are MPC kinds are real theoretical entities insofar as they are stable objects (i.e., neurobiological kinds) despite the fact that their classifications (e.g., 'schizophrenia,' 'bipolar disorder') have looping effects. 
psychiatric kinds. In the case of schizophrenia, the fact that antipsychotic drugs are dopamine antagonists and that their antipsychotic effects are due to their capacity to block $\mathrm{D}_{2}$ dopamine receptors facilitated the original formulation of the dopamine hypothesis that maintains that schizophrenia is caused by excessive dopamine activity. In research on the neurobiology of depression, the “monoamine hypothesis” (Hirschfeld, 2000; López-Muñoz \& Alamo, 2009) that maintains that depression is caused by deficient activity of monoamine neurotransmitters (i.e., norepinephrine, dopamine, and serotonin) was formulated primarily based on the fact that antidepressant drugs that could treat depression (e.g., MAO inhibitors, tricyclic drugs, SSRIs) are all monoamine agonists, which increase the activity of these neurotransmitters (McKim, 2007, ch. 14). The role that drugs play in generating neurobiological hypotheses is particularly notable in neurobiological research on panic disorder. In this domain, researchers utilize "challenge studies” that identify which pharmacological agents (e.g., sodium lactate, carbon dioxide, cholecystokinin tetrapeptide) can induce panic attacks (Cox \& Taylor, 1999). On the basis of these provocation studies, researchers make causal inferences to generate hypotheses about the possible neurobiological causes of panic disorder (e.g., dysregulation in norepinephrine and serotonin systems).

The way in which pharmacological interventions facilitate the generation of causal neurobiological hypotheses exemplifies the interventionist kind of causal reasoning that has been examined comprehensively by James Woodward (2003a, 2003b). Woodward (2003b, ch. 2) advocates a manipulability account of causation that maintains that variable $A$ is a cause of variable $B$ if an intervention that can change the value of $A$ results in a corresponding change in 
the value of $B .^{12}$ This account of causation is motivated, in part, to capture the role of experimentation in causal inference. On Woodward's view, experimentation is relevant to the generation of causal claims because these claims have implications concerning what would happen to $B$ under appropriate interventions of $A$. This suggests that scientists can distinguish genuine causal relationships between variables (from mere correlations) by means of experimental interventions (cf. Thagard, 1999, chs. 7—8). From this perspective, pharmacological drugs can be viewed as facilitating the generation and formulation of causal hypotheses by providing a means for manipulating variables that are causally relevant to mental disorders. For example, in schizophrenia research, the original dopamine hypothesis that suggested that excessive dopamine activity causes the positive symptoms of schizophrenia was inferred primarily through pharmacological interventions. In this case, one pharmacological intervention (administering antipsychotic drugs) changes the value of $A$ (decreases dopamine activity), which results in a corresponding change in $B$ (alleviates positive symptoms). Conversely, another pharmacological intervention (administering high doses of stimulants) changes the value of $A$ (increases dopamine activity), which results in the corresponding change in $B$ (induces positive symptoms). Taken together, these pharmacological interventions strongly suggested the hypothesis that $A$ (increased dopamine activity) causes $B$ (the positive symptoms of schizophrenia).

\subsection{Testing and confirming neurobiological theories}

An important experimental function that pharmacological drugs serve in the context of justification is to aid in the testing and confirmation of neurobiological theories. Once a

\footnotetext{
${ }^{12}$ Woodward (2003b, ch. 1) argues that causal relations should be regarded as relationships that can be exploited for manipulation and control. This stance on causation fits well with the kinds of causal relationships that are of interest within psychiatry (cf. Woodward, 2008) and the neurosciences more generally (Craver, 2007, ch. 3).
} 
neurobiological hypothesis such as the dopamine hypothesis is formulated, drugs are one of the central instruments employed in the testing of hypotheses. In carrying out this role, pharmacological research provides a crucial source of evidence for believing in a neurobiological theory (or conversely, reasons for rejecting or revising a theory). In the case of schizophrenia, the revised dopamine hypothesis that maintains that schizophrenia is caused by a dysregulation of dopamine implies at least three sub-theses:

(1) The positive (psychotic) symptoms of schizophrenia are caused by excessive dopamine activity in the mesolimbic pathway.

(2) The negative symptoms of schizophrenia are caused by deficient dopamine activity in the mesocortical pathway (especially the prefrontal cortex).

(3) Deficient dopamine activity in the mesocortical pathway (especially the prefrontal cortex) causes excessive dopamine activity in the mesolimbic pathway.

As discussed in the previous section, all of these sub-theses of the dopamine hypothesis are supported by multiple lines of pharmacological research. For example, sub-thesis (1) is primarily supported by the findings that: (i) antipsychotic drugs that decrease dopamine activity in the mesolimbic pathway can effectively alleviate positive symptoms, (ii) the antipsychotic effect of such drugs is directly correlated with dopamine blockade strength, (iii) typical antipsychotic drugs exert their influence by blocking $\mathrm{D}_{2}$ dopamine receptors, and (iv) dopamine agonists that increase dopamine activity in the mesolimbic pathway can induce positive symptoms. Taken together, these various pharmacological findings constitute cogent evidence for believing subthesis (1). 
The way in which pharmacological drugs function to aid in the confirmation of a neurobiological hypothesis is amenable to philosophical analyses that suggest that a hypothesis is better supported by evidence when multiple lines of independent research converge upon a common hypothesis (e.g., see Wimsatt, 1981, 2007, ch. 4; Hacking, 1981; Franklin \& Howson, 1984; Trout, 1993; Culp, 1994, 1995; Wylie, 2002, ch. 14; Chang, 2004, ch. 1; Staley, 2004; Stegenga, 2009). These analyses maintain that a scientific hypothesis or theory is "robust" (i.e., well-confirmed) when multiple lines of (at least partially) independent research all point to a common result. The revised dopamine hypothesis of schizophrenia is robust in this sense insofar as multiple lines of independent research support the theory that schizophrenia is caused by a dysregulation of dopamine in the mesolimbic and mesocortical systems. ${ }^{13}$ In this regard, it is important to note that pharmacological interventions only constitute one important part of a larger assemblage of research that contributes to the confirmation of the dopamine hypothesis. For example, sub-thesis (2) of the dopamine hypothesis is supported by the findings that: (i) typical antipsychotic drugs, which decrease dopamine activity in the prefrontal cortex, exacerbate negative symptoms and cause cognitive impairment, (ii) atypical antipsychotic drugs, which increase dopamine activity in the prefrontal cortex, can alleviate negative symptoms, (iii) NMDA antagonists, which depress dopamine activity in the prefrontal cortex, cause cognitive impairment, (iv) the prefrontal cortex plays a role in speech, decision making, and goal-directed behaviors, which are all disrupted in schizophrenia, (v) cognitive impairment is associated deficient dopamine activity in the prefrontal cortex, (vi) compared to normal subjects, schizophrenic patients perform poorly on cognitive tasks designed to measure functions

\footnotetext{
${ }^{13}$ My argument that there is good evidence for the dopamine hypothesis opposes Kendler and Schaffner's (2011) analysis that concludes that evidence in favor of the dopamine hypothesis is lacking. While these authors contend that there is no "direct" evidence for the dopamine hypothesis, my argument assumes an alternative conception of evidence (viz., robustness).
} 
promoted by the prefrontal region, and (vii) brain imaging studies demonstrate that, compared to normal subjects, schizophrenic patients fail to show activation in the dorsal prefrontal cortex while performing cognitive tasks (Kring et al., 2007, pp. 366—367; Carlson, 2008, p. 466467). Within this research, (i) - (iii) are obtained through interventions with pharmacological drugs, whereas (iv)—(vii) are obtained using alternative research methods (e.g., brain imaging studies, cognitive task studies). This clarifies the sense in which pharmacological interventions play an important—but only partial—role in facilitating the testing and confirmation of neurobiological theories (cf. Bechtel, 2008, pp. 34-39).

\subsection{Revising neurobiological theories}

An especially valuable experimental function that pharmacological drugs play in the context of discovery is to promote the refinement, elaboration, and revision of neurobiological theories. As is evident in the historical development of neurobiological theories of schizophrenia, pharmacological drugs played a central role in elaborating and expanding the dopamine hypothesis. In this process, researchers used the known causal effects of typical and atypical antipsychotic drugs to revise the hypothesis that schizophrenia is caused by excessive dopamine activity to the hypothesis that schizophrenia is caused by a dysregulation of dopamine. Moreover, knowledge about the different clinical profiles of antipsychotic drugs (in conjunction with knowledge about different dopamine systems in the brain) allowed researchers to discriminate distinct neurobiological causes (e.g., excessive dopamine activity in the mesolimbic pathway, deficient dopamine activity in the mesocortical pathway) for different schizophrenic symptoms (e.g., positive symptoms, negative symptoms). An important technique that researchers utilized to gain such knowledge is the comparison of antipsychotic drugs with 
clinical profiles that vary in slight ways (e.g., having a higher affinity for $\mathrm{D}_{2}$ receptors, having a stronger serotonin blockade effect), which allowed for causal inferences to be drawn based on the differential response of patients to such drugs. ${ }^{14}$ The formulation of the revised dopamine hypothesis was also facilitated by experimental knowledge gained with other pharmacological drugs (e.g., stimulant drugs, hallucinogen drugs), which has implicated the importance of other neurotransmitters—such as glutamate and serotonin—in the neurobiology of schizophrenia.

The way in which pharmacological research facilitates the refinement and revision of neurobiological theories of schizophrenia highlights the dynamic and interactive relationship between clinical contexts (applied science) and research contexts (pure science) in psychiatry (cf. Adam, 2005). While pharmacological research is motivated primarily to design better pharmacological treatments for schizophrenia in clinical contexts, the drugs that are developed often play a crucial role in assisting researchers to expand and revise existing neurobiological theories of mental disorders in research contexts. Martin Carrier (2004a, 2010) has argued that the aims of applied science (i.e., pragmatic control)—which are embedded in a particular context of interests, values, and practical problems—do not necessarily compromise the aims of pure science (i.e., knowledge acquisition). Moreover, he suggests that innovations in pure science often arise through applied research projects, which is a process he calls application innovation (Carrier, 2004a, 2004b, 2010). The ways in which neurobiological theories of schizophrenia have been expanded and revised through applied research in pharmacology represent a particularly salient example of application innovation. Conversely, theoretical innovations in neurobiological research often feed back into applied contexts to facilitate the development of better pharmacological treatments (Thagard, 2003, 2008). For instance, research efforts to demonstrate

\footnotetext{
${ }^{14}$ In this regard, the ability of pharmacologists to develop partial agonist drugs—-which have a high affinity for particular receptors, but which activate the receptor less than the normal ligand (Carlson, 2008, p. 469) —serve as especially useful experimental tools.
} 
that the antipsychotic effect of drugs can be decoupled from the appearance of EPS was a key innovation that led to the development of atypical antipsychotic drugs, which were subsequently utilized in clinical contexts. This illustrates the manner in which applied and pure contexts in psychiatry stand in an interactive and complementary relationship.

\section{Conclusion}

In this paper, I examined the role of pharmacological drugs as experimental instruments in the context of research on the neurobiology of mental disorders, focusing on the example of antipsychotic drugs and schizophrenia. My analysis was intended to show that pharmacological treatments of psychiatric patients in clinical contexts often serve to inform neurobiological theories of mental disorders in research contexts. Besides providing clinicians with methods for treating patients with schizophrenia, research on pharmacological drugs provides psychiatrists with important insights about the neurobiological basis of mental disorders. I suggested that four important functions of pharmacological drugs as experimental instruments are: (1) providing tools to access and detect stable neurobiological kinds, (2) suggesting neurobiological hypotheses, (3) testing neurobiological theories, and (4) facilitating the revision of neurobiological theories. In the historical development of the dopamine theory of schizophrenia, antipsychotic drugs (as well as other pharmacological drugs) performed all of these functions.

Examining the ways that pharmacological research contribute to neurobiological knowledge about mental disorders underscores the importance of intervention and causal reasoning in the generation of psychiatric knowledge. In this process, pharmacological drugs are experimental instruments that provide researchers with a means for accessing and manipulating the complex neurobiological causal structure of mental disorders such as schizophrenia. In 
observing the differential response of psychiatric patients to different pharmacological treatments, researchers are able to make inferences about the neurobiological causes for different psychological and behavioral symptoms. While these interventions and causal inferences do not produce psychiatric knowledge that is infallible or immune to revision, they are indispensible in the formulation, testing, and development of neurobiological knowledge about mental disorders.

\section{Acknowledgements}

I am grateful to Ian Hacking, Bill Wimsatt, Kathryn Tabb, Lara Kutschenko, Emma Tobin, Robyn Bluhm, Allan Franklin, Ruey-Lin Chen, Alan Love, Kenneth Waters, and an anonymous referee for helpful comments and suggestions. Earlier drafts of this paper were presented at the third biennial conference of the Society of Philosophy of Science in Practice (SPSP) at the University of Exeter in June 2011 and at the Minnesota Center for Philosophy of Science Biological Interest Group (BIG) seminar at the University of Minnesota in September 2011. I am grateful for feedback that I received on those occasions. Special thanks to Kutschenko and Tabb for co-organizing our symposium ("Philosophy of Psychiatry in Practice: Steps towards an Adequate Theory of Psychiatric Classification”) at the SPSP conference.

\section{References}

Abi-Dargham, A. (2004). Do we still believe in the dopamine hypothesis? New data bring new evidence. International Journal of Neuropsychopharmacology, 6 (Suppl.), S1—S5.

Ackermann, R. J. (1985). Data, instruments, and theory: A dialectical approach to the understanding of science. Princeton, NJ: Princeton University Press.

Adam, M. (2005). Integrating research and development: The emergence of rational drug design 
in the pharmaceutical industry. Studies in History and Philosophy of Biological and Biomedical Sciences, 36, 513-537.

Andreasen, N. C, and Olsen, S. (1982). Negative $v$ positive schizophrenia: Definition and validation. Archives of General Psychiatry, 39, 789—794.

Angrist, B. M., \& Gershon, S. (1970). The phenomenology of experimentally induced amphetamine psychosis: Preliminary observations. Biological Psychiatry, 2, 95—107.

Angst, J., Jaenicke, U., Padrutt, A., \& Scharfetter, C. (1971). Ergebnisse eines Doppelblindversuchs von Clozapin (8-Chlor-11-(4-methyl-1-piperazinyl)-5-Hdibenzo(b,e)(1,4)diazepin im Vergleich zu Levomepromazin. Pharmakopsychiatrie, 4, $192-200$.

Ayd, F. J. (1961). A survey of drug-induced extrapyradmidal reactions. Journal of the American Medical Association, 175, 1054-1060.

Ban, T. A. (1994). Nobel Prize and Albert Lasker Award. In T. A. Ban \& H. Hippius (Eds.), Towards CINP (pp. 8-14). Brentwood, TN: JM Productions.

Ban, T. A. (2007). Fifty years chlorpromazine: A historical perspective. Neuropsychiatric Disease and Treatment, 3, 495-500.

Baumeister, A. A., \& Hawkins, M. F. (2005). Continuity and discontinuity in the historical development of modern psychopharmacology. Journal of the History of the Neurosciences, 14, 199—209.

Bechtel, W. (2008). Mental mechanisms: Philosophical perspectives on cognitive neuroscience. New York: Routledge.

Bechtel, W., \& Richardson, R. C. (1993). Discovering complexity: Decomposition and localization as strategies in scientific research. Princeton, NJ: Princeton University 
Press.

Bell, D. S. (1973). The experimental reproduction of amphetamine psychosis. Archives of General Psychiatry, 29, 35-40.

Bente, D., Engelmeier, M.-P., Heinrich, K., Schmitt, W., \& Hippius, H. (1966). Klinische Untersungen mit einem neuroleptisch wirksamen Dibenzothiazepin-Derivat. Arzneimittelforschung, 16, 314-316.

Bhatara, V. S., López-Muñoz, R., \& Gupta, S. (2005). Celebrating the 50th anniversary of the introduction of chlorpromazine in North America and the advent of the psychopharmacology revolution. Annals of Clinical Psychiatry, 17, 109-111.

Carlson, N. R. (2008). Foundations of physiological psychology (7th ed.). Boston, MA: Allyn and Bacon.

Carlsson, A., \& Lindqvist, M. (1963). Effect of chlorpromazine or haloperidol on formation of 3-methoxytyramine and normetanephrine in mouse brain. Acta Pharmacologica et Toxicology, 20, 140-144.

Carlsson, A., Waters, N., Holm-Waters, S., Tedroff, J., Nilsson, M., \& Carlsson, M. L. (2001). Interactions between monoamines, glutamate, and GABA in schizophrenia: New evidence. Annual Review of Pharmacology and Toxicology, 41, 237-260.

Carr, D. B., \& Sesack, S. R. (2000). Projections from the rat prefrontal cortex to the ventral tegmental area: Target specificity in the synaptic associations with mesoaccumbens and mesocortical neurons. Journal of Neuroscience, 20, 3864-3873.

Carrier, M. (2004a). Knowledge and control: On the bearing of epistemic values in applied science. In P. Machamer \& G. Wolters (Eds.), Science, values, and objectivity (pp. 275293). Pittsburgh, PA: University of Pittsburgh Press. 
Carrier, M. (2004b). Knowledge gain and practical use: Models in pure and applied research. In D. Gillies (Ed.), Laws and models in science (pp. 1-17). London: King’s College Publications.

Carrier, M. (2010). Theories for use: On the bearing of basic science on practical problems. In M. Suárez, M. Dorato, \& M. Rédei (Eds.), EPSA epistemology and methodology of science: Launch of the European Philosophy of Science Association (pp. 23-33). Dordrecht: Springer.

Cartwright, N. (1983). How the laws of physics lie. Oxford: Oxford University Press.

Chang, H. (2004). Inventing temperature: Measurement and scientific progress. Oxford: Oxford University Press.

Cox, B. J., \& Taylor, S. (1999). Anxiety disorders: Panic and phobias. In T. Millon, P. H. Blaney, \& R. D. Davis (Eds.), Oxford textbook of psychopathology (pp. 81-113). New York: Oxford University Press.

Coyle, J. T. (2006). Glutamate and schizophrenia: Beyond the dopamine hypothesis. Cellular and Molecular Neurobiology, 26, 4-6.

Craver, C. F. (2007). Explaining the brain: Mechanisms and the mosaic unity of neuroscience. Oxford: Oxford University Press.

Craver, C. F., \& Darden, L. (2001). Discovering mechanisms in neurobiology: The case of spatial memory. In P. K. Machamer, R. Grush, \& P. McGlaughlin (Eds.), Theory and method in the neurosciences (pp. 112—137). Pittsburgh, PA: University of Pittsburgh Press.

Creese, I., Burt, D. R., \& Snyder, S. H. (1976). Dopamine receptor binding predicts clinical and pharmacological potencies of antischizophrenic drugs. Science, 192, 481—483. 
Crow, T. J. (1980a). Molecular pathology of schizophrenia: More than one disease process? British Medical Journal, 280, 1-9.

Crow, T. J. (1980b). Positive and negative schizophrenia symptoms and the role of dopamine. British Journal of Psychiatry, 137, 383-386.

Culp, S. (1994). Defending robustness: The bacterial mesosome as a test case. In D. Hull, M. Forbes, \& R. M. Burian (Eds.), PSA 1994: Proceedings of the 1994 Biennial Meeting of the Philosophy of Science Association (Vol. 1, pp. 46-57). East Lansing, MI: Philosophy of Science Association.

Culp, S. (1995). Objectivity in experimental inquiry: Breaking data-technique circles. Philosophy of Science, 62, 430—450.

Davis, K. L., Kahn, R. S., Ko, G., \& Davidson, M. (1991). Dopamine in schizophrenia: A review and reconceptualization. American Journal of Psychiatry, 148, 1474—1486.

Delay, J., \& Deniker, P. (1952a). 38 cas de psychoses traitées par la cure prolongée et continué de 4560 RP. Comptes rendus du 50e congrès des médecins aliénistes et neurologistes de France et des pays de langue française, 50, 503-513..

Delay, J., \& Deniker, P. (1952b). Le traitements de psychoses par une methode neurolytique dérivée de l’hibernothérapie (le 4560 RP utilisée seul en cure prolongée et continue). Comptes rendus du 50e congrès des médecins aliénistes et neurologistes de France et des pays de langue française, 50, 497—502.

Delay J., \& Deniker, P. (1952c). Réactions biologiques observées au cours du traitement par le Chlorte de diméthylaminopropyl-N-chlorophénothiazine. Comptes rendus du 50e congrès des médecins aliénistes et neurologistes de France et des pays de langue française, 50, $514-518$. 
Delay, J., Deniker, P., \& Harl, J. M. (1952a). Traitement des états d'excitation et d'agitation par une méthode médicamenteuse dérivée de l’hibernothérapie. Annales medicopsychologiques, 110, 267-273.

Delay, J., Deniker, P., \& Harl, J. M. (1952b). Utilisation en thérapeutique psychiatrique d'une phénothiazine d'action centrale élective. Annales medico-psychologiques, 110, 112— 117.

Delay, J., Deniker, P., Harl, J. M., \& Grasset, A. (1952). Traitement d'états confusionnels par le Chlorte de diméthylaminopropyl-N-chlorophénothiazine (4560 RP). Annales medicopsychologiques, 110, 398-403.

Ellinwood, E. H. (1967). Amphetamine psychosis: I. Description of the individuals and process. Journal of Nervous Mental Disease, 144, 273—283.

Ellinwood, E. H., Sudilovsky, A., \& Nelson, L. M. (1973). Evolving behavior in the clinical and experimental amphetamine (model) psychosis. American Journal of Psychiatry, 130, 1088-1093.

Frankenburg, F. R. (1994). History of the development of antipsychotic medication. Psychiatric Clinics of North America, 17, 531—540.

Franklin, A. (1986). The neglect of experiment. Cambridge: Cambridge University Press.

Franklin, A. (1996). There are no antirealists in the laboratory. In R. S. Cohen, R. Hilpinen, \& Q. Renzong (Eds.), Realism and antirealism in the philosophy of science (pp. 131-148). Dordrecht: Kluwer Academic Publishers.

Franklin, A. (2010). Experiment in physics. In E. N. Zalta (Ed.), The Stanford encyclopedia of philosophy (Spring 2010 ed.). http://plato.stanford.edu/archives/spr2010/entries/physics-experiment/

Franklin, A., \& Howson, C. (1984). Why do scientists prefer to vary their experiments? Studies 
in History and Philosophy of Science, 15, 51—62.

Galison, P. (1987). How experiments end. Chicago: University of Chicago Press.

Giere, R. N. (1988). Explaining science: A cognitive approach. Chicago: University of Chicago Press.

Glennan, S. (1996). Mechanisms and the nature of causation. Erkenntnis, 44, 49—71.

Glennan, S. (2002). Rethinking mechanistic explanation, Philosophy of Science, 69, S342S353.

Goff, D. C., \& Coyle, J. T. (2001). The emerging role of glutamate in the pathophysiology and treatment of schizophrenia. American Journal of Psychiatry, 158, 1367-1377.

Griffiths, J. J., Oates, J., \& Cavanaugh, J. (1968). Paranoid episodes induced by drugs. Journal of the American Medical Association, 205, 39—46.

Grob, G. N. (1991). From asylum to community: Mental health policy in modern America. Princeton, NJ: Princeton University Press.

Grob, G. N. (1995). The paradox of deinstitutionalization. Society, 32, 51—59.

Gross, H., \& Langner, E. (1966). Das Wirkungsprofil eines chemisch neuartigen Breitbandneuroleptikums der Dibenzodiazepingruppe. Wiener Medizinische Wochenschrift, 116, 814-816.

Hacking, I. (1981). Do we see through a microscope? Pacific Philosophical Quarterly, 63, 305322.

Hacking, I. (1983). Representing and intervening: Introductory topics in the philosophy of natural science. Cambridge: Cambridge University Press.

Hacking, I. (1999). The social construction of what? Cambridge, MA: Harvard University Press.

Hacking, I. (2007). Kinds of people: Moving targets. Proceedings of the British Academy, 151, 285-318.

Healy, D. (1997). The anti-depressant era. Cambridge, MA: Harvard University Press. 
Healy, D. (2002). The creation of psychopharmacology. Cambridge, MA: Harvard University Press.

Healy, D. (2004). Drug regulation and the introduction of psychotropic drugs in the United Kingdom. In T. A. Ban, D. Healy, \& E. Shorter (Eds.), Reflections on twentiethcentury psychopharmacology (pp. 94-97). Budapest: Animula.

Hippius, H. (1989). The history of clozapine. Psychopharmacology, 99 (Suppl.), S3—S5.

Hippius, H. (1996). The founding of the CINP and the discovery of clozapine. In D. Healy (Ed.), The psychopharmacologists: Interviews (Vol. 1, pp. 187-214). London: Chapman and Hall.

Hirschfeld, R. M. A. (2000). History and evolution of the monoamine hypothesis of depression. Journal of Clinical Psychiatry, 61 (Suppl. 6), 4—6.

Howes, O. D., \& Kapur, S. (2009). The dopamine hypothesis of schizophrenia: Version III—the final common pathway. Schizophrenia Bulletin, 35, 549—562.

Janowsky, D. S. (2004). The history of psychotropic drugs in the United States. In T. A. Ban, D. Healy, \& E. Shorter (Eds.), Reflections on twentieth-century psychopharmacology (pp. 77-82). Budapest: Animula.

Jentsch, J. D., \& Roth, R. H. (1999). The neuropsychopharmacology of phencyclidine: From NMDA receptor hypofunction to the dopamine hypothesis of schizophrenia. Neuropsychopharmacology, 20, 201-225.

Jentsch, J. D., Taylor, J. R., Elsworth, J. D., Redmond, D. E., \& Roth, R. H. (1999). Altered frontal cortical dopaminergic transmission in monkeys after subchronic phencyclidine exposure: Involvement in frontostriatal cognitive deficits. Neuroscience, 90, 823—832.

Jentsch, J. D., Tran, A., Taylor, J. R., \& Roth, R. H. (1998). Prefrontal cortical involvement in phencyclidine-induced activation of the mesolimbic dopamine system: Behavioral and neurochemical evidence. Psychopharmacology, 138, 89—95. 
Kane, J., Honigfeld, G., Singer, J., Meltzer, H., \& the Clozaril Collaborative Study Group (1988). Clozapine for the treatment-resistant schizophrenic: A double blind comparison with chlorpromazine. Archives of General Psychiatry, 11, 193-198.

Kendler, K. S., \& Schaffner, K. F. (2011). The dopamine hypothesis of schizophrenia: An historical and philosophical analysis. Philosophy, Psychiatry, \& Psychology, 18, 41—63.

Kendler, K. S., Zachar, P., \& Craver (2011). What kinds of things are psychiatric disorders? Psychological Medicine, 41, 1143-1150.

King, C., \& Voruganti, L. N. P. (2002). What's in a name? The evolution of the nomenclature of antipsychotic drugs. Journal of Psychiatry \& Neuroscience, 27, 168-175.

Kring, A. M., Davison, G. C., Neale, J. M., \& Johnson, S. L. (2007). Abnormal psychology (10th ed.). Hoboken, NJ: John Wiley \& Sons.

Labhardt, F. (1954). Die Largactiltherapie bei Schizophrenien und anderen psychotischen Zuständen. Schweizer Archiv für Neurologie und Psychiatrie, 73, 309—338.

Laborit, H., \& Huguenard, P. (1951). L'hibernation artificielle par moyens pharmacodynamiques of physiques. La presse médicale, 59, 1329.

Laborit, H., Huguenard, P., \& Alluaume, R. (1952). Un nouveau stabilisateur vegetative (le 4560 RP). La presse médicale, 60, 206-208.

Landwehrmeyer, B., Mengod, G., \& Palacios, J. M. (1993). Dopamine D3 receptor mRNA and binding sites in human brain. Molecular Brain Research, 18, 187-192.

Laruelle, M., Kegeles, L. S., \& Abi-Dargham, A. (2003). Glutamate, dopamine, and schizophrenia. Annals of the New York Academy of Sciences, 1003, 138-158.

Lehmann, H. E. (1954). Selective inhibition of affective drive by pharmacological means. American Journal of Psychiatry, 110, 856—857.

Lehmann, H. E., \& Hanrahan, G. E. (1954). Chlorpromazine: New inhibiting agent for 
psychomotor excitement and manic states. Archives of Neurology and Psychiatry, 71, 227-237.

López-Muñoz, F., \& Alamo, C. (2009). Monoaminergic neurotransmission: The history of the discovery of antidepressants from 1950s to today. Current Pharmaceutical Design, 15, $1563-1586$.

López-Muñoz, F., Alamo, C., Ceunza, E., Shen, W. W., Clervoy, P., \& Rubio, G. (2005). History of the discovery and clinical introduction of chlorpromazine. Annals of Clinical Psychiatry, 17, 113-135.

López-Muñoz, F., Alamo, C., Jeckel, G., \& Assion, H.-J. (2007). Half a century of antidepressant drugs: On the clinical introduction of monoamine oxidase inhibitors, tricyclics, and tetracyclics. Part I: Monoamine oxidase inhibitors. Journal of Clinical Psychopharmacology, 27, 555-559.

Machamer, P. (2004). Activities and causation: The metaphysics and epistemology of mechanisms. International Studies in the Philosophy of Science, 18, 27-39.

Machamer, P., Darden, L., \& Craver, C. F. (2000). Thinking about mechanisms. Philosophy of Science, $67,1-25$.

Matthysse, S. (1973). Antipsychotic drug actions: A clue to the pathology of schizophrenia. Federation Proceedings, 32, 200—205.

McKim, W. A. (2007). Drugs and behavior: An introduction to behavioral pharmacology (6th ed.). Upper Saddle River, NJ: Pearson Prentice Hall.

Meltzer, H. Y., \& Stahl, S. M. (1976). The dopamine hypothesis of schizophrenia: A review. Schizophrenia Bulletin, 2, 19-76.

Meyer, J. M., \& Simpson, G. M. (1997). From chlorpromazine to olanzapine: A brief history of antipsychotics. Psychiatric Services, 48, 1137-1139. 
Morrison, M. (1990). Theory, intervention, and realism. Synthese, 82, 1-22.

Olney, J. W., \& Farber, N. B. (1995). Glutamate receptor dysfunction and schizophrenia. Archives of General Psychiatry, 52, 998-1007.

Primus, R. J, Thurkauf, A., Xu, J., Yevich, E., McInerney, S., Shaw, K., Tallman, J. F, \& Gallagher, D. W. (1997). II. Localization and characterization of dopamine D4 binding sites in rat and human brain by use of the novel, D4 receptor-selective ligand [3H]NGD 94-1. Journal of Pharmacology and Experimental Therapy, 282, 1020-1027.

Radden, J. (2003). Is this dame Melancholy? Equating today’s depression and past melancholia. Philosophy, Psychiatry, \& Psychology, 10, 37-52.

Radden, J. (2009). Moody minds distempered: Essays on melancholy and depression. Oxford: Oxford University Press.

Radder, H. (Ed.) (2003). The philosophy of scientific experimentation. Pittsburgh, PA: University of Pittsburgh Press.

Sawaguchi, T., \& Goldman-Rakic, P. S. (1994). The role of D1-dopamine receptor in working memory: Local injections of dopamine antagonists into the prefrontal cortex of rhesus monkeys performing an oculomotor delayed-response task. Journal of Neurophysiology, $71,515-528$.

Schaffner, K. F. (1993). Discovery and explanation in biology and medicine. Chicago: University of Chicago Press.

Seeman, P. (1987). Dopamine receptors and the dopamine hypothesis of schizophrenia. Synapse, $1,133-152$.

Seeman, P., \& Lee, T. (1975). Antipsychotic drugs: Direct correlation between clinical potency and presynaptic action on dopamine neurons. Science, 188, 1217-1219.

Seeman, P., Lee, T., Chau-Wong, M., \& Wong, K. (1976). Antipsychotic drug doses and neuroleptic/dopamine receptors. Nature, 261, 717-719.

Seeman, P., \& van Tol, H. H. (1994). Dopamine receptor pharmacology. Trends in 
Pharmacological Science, 15, 264-270.

Shen, W. W. (1994). Pharmacotherapy of schizophrenia: The American current status. Keio Journal of Medicine, 43, 192-200.

Shen, W. W. (1999). A history of antipsychotic drug development. Comprehensive Psychiatry, 40, 407-414.

Staley, K. W. (2004). Robust evidence and secure evidence claims. Philosophy of Science, 71, 467-488.

Stegenga, J. (2009). Robustness, discordance, and relevance. Philosophy of Science, 76, 650661.

Strauss, J. S., Carpenter, W. T. \& Bartko, J. J. (1974). Speculations on the processes that underlie schizophrenic symptoms and signs. Schizophrenia Bulletin, 11, 61—69.

Tabery, J. G. (2004). Synthesizing activities and interactions in the concept of a mechanism. Philosophy of Science, 71, 1-15.

Tamminga, C. A. (1998). Schizophrenia and glutamatergic transmission. Critical Reviews in Neurobiology, 12, 21-36.

Thagard, P. (1999). How scientists explain disease. Princeton, NJ: Princeton University Press.

Thagard, P. (2003). Pathways to biomedical discovery. Philosophy of Science, 70, 235—254.

Thagard, P. (2008). Mental illness from the perspective of theoretical neuroscience. Perspectives in Biology and Medicine, 51, 335-352.

Trout, J. D. (1993). Robustness and integrative survival in significance testing: The world's contribution to rationality. British Journal for the Philosophy of Science, 44, 1-15.

Tsou, J. Y. (2007). Hacking on the looping effects of psychiatric classifications: What is an interactive and indifferent kind? International Studies in the Philosophy of Science, 21, $329-344$.

Tsou, J. Y. (2011). The importance of history for philosophy of psychiatry: The case of the DSM 
and psychiatric classification. Journal of the Philosophy of History, 5, 446-470.

van Rossum, J. M. (1966). The significance of dopamine-receptor blockade for the mechanism of action of neuroleptic drugs. Archives of International Pharmacodynamic Therapy, $160,492-494$.

van Rossum, J. M. (1967). The significance of dopamine-receptor blockade for the action of neuroleptic drugs. In H. Brill, J.O. Cole, P. Deniker, H. Hippius, \& P. B. Bradley (Eds.), Neuro-psychopharmacology: Proceedings of the Fifth International Congress of the Collegium Internationale Neuro-Psychopharmacologicum (pp. 321-329). Amsterdam: Excerpta Medica Foundation.

Wheatley, D. (2004). The history of psychotropic drugs in the United Kingdom. In T. A. Ban, D. Healy, \& E. Shorter (Eds.), Reflections on twentieth-century psychopharmacology (pp. 83-93). Budapest: Animula.

Wimsatt, W. C. (1981). Robustness, reliability, and overdetermination. In M. B. Brewer \& B. E. Collins (Eds.), Scientific inquiry and the social sciences (pp. 124-163). San Francisco, CA: Jossey-Bass.

Wimsatt, W. C. (2007). Re-engineering philosophy for limited beings: Piecewise approximations to reality. Cambridge, MA: Harvard University Press.

Wing, J. K. (1978). Clinical concepts of schizophrenia. In J. K. Wing (Ed.) Schizophrenia: Towards a new synthesis (pp. 1-30). New York: Grune \& Stratton.

Woodward, J. (2003a). Experimentation, causal inference, and instrumental realism. In H. Radder (Ed.), The philosophy of scientific experimentation (pp. 87-118). Pittsburgh, PA: University of Pittsburgh Press.

Woodward, J. (2003b). Making things happen: A theory of causal explanation. Oxford: Oxford University Press.

Woodward, J. F. (2008). Cause and explanation in psychiatry: An interventionist perspective. In 
K. S. Kendler \& J. Parnas (Eds.), Philosophical issues in psychiatry: Explanation, phenomenology, and nosology (pp. 132—195). Baltimore, MD: Johns Hopkins University Press.

Wylie, A. (2002). Thinking from things: Essays in the philosophy of archaeology. Berkeley, CA: University of California Press.

Youngren, K. D., Inglis, F. M., Pivirotto, P. J., Jedema, H. P., Bradberry, C. W., Goldman-Rakic, P. S., Roth, R. H., \& Modhaddam, B. (1999). Clozapine preferentially increases dopamine release in the rhesus monkey prefrontal cortex compared with the caudate nucleus. Neuropsychopharmacology, 20, 403-412. 